\title{
CLINICAL RESEARCH
}

\section{Effect of plasma exchange on blood viscosity and cerebral blood flow}

\author{
M M BROWN, JOHN MARSHALL
}

\begin{abstract}
The effects of plasma exchange using a low viscosity plasma substitute on blood viscosity and cerebral blood flow were investigated in eight subjects with normal cerebral vasculature. Plasma exchange resulted in significant reductions in plasma viscosity, whole blood viscosity, globulin and fibrinogen concentration without affecting packed cell volume. The reduction in whole blood viscosity was more pronounced at low shear rates suggesting an additional effect on red cell aggregation. Despite the fall in viscosity there was no significant change in cerebral blood flow. The results support the metabolic theory of autoregulation. Although changes in blood viscosity appear not to alter the level of cerebral blood flow under these circumstances, plasma exchange could still be of benefit in the management of acute cerebrovascular disease.
\end{abstract}

\section{Introduction}

Under certain defined circumstances the flow of liquids in narrow tubes is inversely proportional to the viscosity of the fluid. Flow conditions in the microcirculation are of the right order for viscous forces to dominate flow. ${ }^{1}$ Changes in blood viscosity could therefore affect cerebral blood flow in the microcirculation if other factors remained unchanged. On the other hand, the cerebral circulation has remarkable powers of homoeostasis which might enable it to adjust for changes in viscosity.

Whole blood viscosity measured in vitro is proportional to the haematocrit. ${ }^{2}$ Haemodilution has therefore been advocated as a treatment for acute stroke in order to reduce blood viscosity and improve cerebral blood flow. ${ }^{3} 4$ Nevertheless, haemodilution also

\footnotetext{
Institute of Neurology and National Hospital for Nervous Diseases, London WC1N 3BG

M M BROWN, BA, MRCP, research fellow

JOHN MARSHALL, D SC, FRCP, professor of clinical neurology
}

results in a reduction of arterial oxygen content by lowering haemoglobin concentration. Arterial oxygen content has an important influence on cerebral blood flow. ${ }^{5}$ The improvements in blood flow after haemodilution may therefore be a physiological response to the reduced oxygen content and not necessarily related to the reduction in viscosity.

Whole blood viscosity also depends on the viscosity of the plasma. Reduction in plasma viscosity could provide a method of lowering whole blood viscosity in patients with vascular disorders without altering haemoglobin concentration or arterial oxygen content. Plasma exchange has been used to lower plasma viscosity in patients with hyperviscosity due to macroglobulinaemia ${ }^{6}$ Raynaud's disease, ${ }^{7}$ and hyperlipoproteinaemia, ${ }^{8}$ but its use for this purpose in subjects with normal plasma viscosity has not been investigated. Also, the normal physiological response of the cerebral circulation to changes in blood viscosity achieved without alterations in arterial oxygen content has not been established. We have therefore studied the effects of plasma exchange using a low viscosity plasma substitute on blood viscosity and cerebral blood flow in haematologically normal patients without vascular disease.

\section{Subjects and methods}

Eight subjects (six men and two women), in whom plasma exchange was carried out as part of their treatment, were studied. The indications were myasthenia gravis (one case), peripheral neuropathy (three cases), Eaton Lambert syndrome (three cases), and macular oedema associated with myeloma (one case). All but two of the subjects had had plasma exchange before, but none was studied less than eight weeks after the previous exchange. All had normal cerebral circulation, normal cardiopulmonary function, and an intact autonomic nervous system. Ages ranged from 26 to 71 years with a mean of 49 years (SD 16).

Plasma exchange-The subjects were studied a few hours before and between 12 and 18 hours after a single session of plasma exchange using a Haemonetics Model 30 blood processor. Of the patients' plasma $50 \mathrm{ml} / \mathrm{kg}$ body weight was exchanged with an equal volume of $5.0 \%$ human albumin plasma protein fraction, which has a viscosity less than that of normal human plasma. During separation blood was anticoagulated with 5000 units calcium heparin in $500 \mathrm{ml} 0.9 \%$ saline. Additional potassium and calcium ions were added during the procedure.

Cerebral blood flow-This was measured by a non-invasive intra- 
venous xenon- 133 clearance technique. ${ }^{9}$ About $7 \mathrm{mCi}$ xenon- 133 was injected intravenously and the clearance of the isotope from the cerebral hemispheres monitored with six external scintillation detectors (25 $\mathrm{mm}$ in diameter). Regional cerebral blood flow was calculated from bicompartmental analysis of the clearance curves according to the method of Obrist et al. ${ }^{10}$ This resulted in figures for volumetric blood flow through the fast clearing tissues of the brain, which are mainly grey matter. The estimation of cerebral blood flow for each subject was taken as the mean of the six regional fast clearing tissue flows. Mean arterial blood pressure and pulse were recorded at the start of the cerebral blood flow measurements. Arterial carbon dioxide pressure $\left(\mathrm{PcO}_{2}\right)$ was estimated by monitoring end-expired carbon dioxide concentrations with a Datex CD 300 infrared carbon dioxide analyser. $\mathrm{PCO}_{2}$ was calculated from the mean end-expiratory carbon dioxide concentrations recorded during the first five minutes of the blood flow measurement.

Blood viscosity-Blood samples for viscosity and haematological investigations were taken at the time of the blood flow measurements was more pronounced at the low shear rate, where mean viscosity was reduced by $43 \%$. This compares with a $14 \%$ mean reduction at the higher shear rate and a $16 \%$ mean reduction in plasma viscosity. Packed cell volume was not significantly affected by the procedure. Total protein, globulin, and fibrinogen concentrations were al significantly reduced. Mean globulin and fibrinogen concentrations were the most influenced, being reduced by $30 \%$ and $40 \%$ respectively. Albumin concentrations rose in most patients, although the mean difference was not significant.

Table II summarises the effects of plasma exchange on cerebra blood flow and the other physiological indices recorded. There was no significant change in cerebral blood flow. There were also no significant alterations in mean arterial blood pressure, pulse, or arterial $\mathrm{PCO}_{2}$ that might have influenced cerebral blood flow. Plasma exchange was achieved without a significant reduction in mean haemoglobin concentration. The latter is the major determinant of arterial oxygen content in subjects with normal blood gases ${ }^{12}$ and it is therefore unlikely that oxygen content was significantly altered by the procedure.

TABLE I-Effect of plasma exchange on blood viscosity in eight subjects. (Figures are means $\pm S D$ )

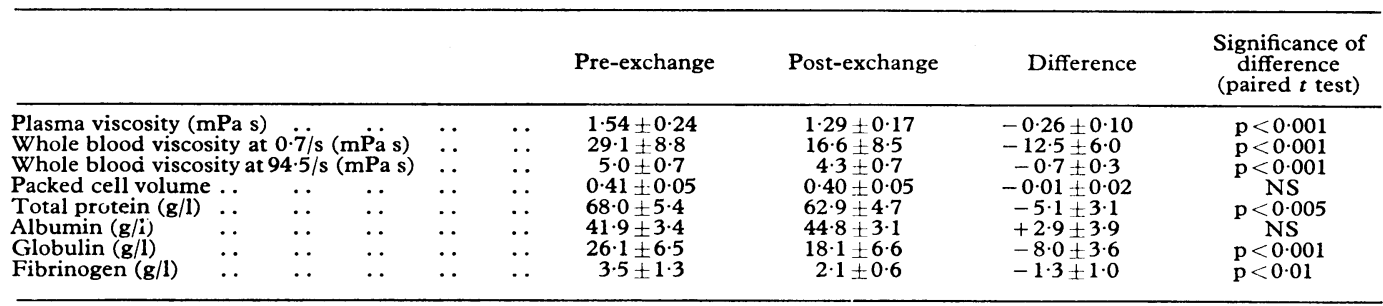

NS $=$ Not significant

TABLE II-Effect of plasma exchange on cerebral blood flow in eight subjects. (Figures are means $\pm S D$ )

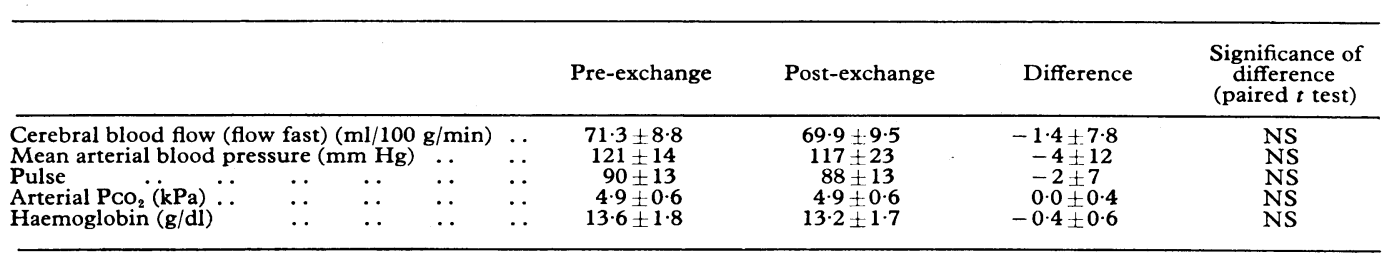

NS = Not significant

without stasis from an antecubital vein with the arm horizontal and the subject recumbent. Samples for viscosity measurements were anticoagulated with lithium heparin and the determinations made within two hours. Whole blood and plasma viscosity were measured at $37^{\circ} \mathrm{C}$ in a Contraves low shear 30 coaxial viscometer coupled to a Rheoscan 20 programmer and an XY recorder. Whole blood samples were subjected to a logarithmic increase in shear rate firstly over a low shear range $(0-1 \cdot 285 / \mathrm{s})$ and immediately afterwards over a higher shear range $(0-128 \cdot 5 / \mathrm{s})$ using a ramp time of one minute. Whole blood viscosity was calculated from the shear stress readings at shear rates of $0.7 / \mathrm{s}$ in the low shear range and $94.5 / \mathrm{s}$ in the higher shear range. Plasma samples were subjected only to the higher shear rate range and plasma viscosity calculated at a shear rate of $94 \cdot 5 / \mathrm{s}$.

Other haematological investigations-Packed cell volume was measured in a Hawksley microhaematocrit centrifuge without correction for trapped plasma. Haemoglobin concentration was determined in a Coulter haemoglobinometer. Total serum protein concentration was analysed by the Buiret method and serum albumin concentration by the bromcresol green technique. Serum globulin concentration was estimated by subtraction of the albumin value from the total protein value. Plasma fibrinogen concentration was determined by a heat precipitation nephalometric method. ${ }^{11}$

\section{Results}

Table I summarises the effects of plasma exchange on blood viscosity and its major determinants in the eight subjects. There was a highly significant reduction in both plasma viscosity and whole blood viscosity in all the subjects. The fall in whole biood viscosity

\section{Discussion}

This study shows that plasma exchange can be effectively used to lower blood viscosity even in subjects with initially normal viscosity. As the packed cell volume was unaltered by the procedure the reduction in whole blood viscosity reflects the reduction in plasma viscosity and the concentration of certain plasma constituents. Fibrinogen and globulin both contribute to the cell protein interaction responsible for red cell aggregation, and this phenomenon leads to whole blood viscosity being higher at low shear rates. ${ }^{13}$ The more pronounced fall in whole blood viscosity at the low shear rate after plasma exchange therefore reflects reduced red cell aggregation as well as an absolute reduction in the viscosity of the plasma component. At the higher shear rate of $94.5 / \mathrm{s}$, which is well above the shear rates when red cell aggregation is important, the percentage fall in whole blood viscosity reflects a similar percentage fall in plasma viscosity.

The main conclusion from the study is that cerebral blood flow remained constant despite the significant reductions in whole blood and plasma viscosity by plasma exchange. The mean difference between the mean flows before and after exchange of $-1.4+7.8 \mathrm{ml} / 100 \mathrm{~g} / \mathrm{min}$ was very similar to the mean difference of $-0 \cdot 1 \pm 9 \cdot 6 \mathrm{ml} / 100 \mathrm{~g} / \mathrm{min}$ obtained between repeated measurements of cerebral blood flow using the same method in normal subjects who have had no intervening procedure. ${ }^{9}$

The direct application of in-vitro measurements of blood viscosity to the in-vivo circumstances has certain limitations. 
Within the circulation blood is subjected to continuously varying shear rates and because the viscosity of blood varies with the shear rate a single measurement of blood viscosity cannot be applied to blood throughout the circulation. Within the microcirculation, however, shear rates are mostly very high, ${ }^{14}$ and measurements of viscosity at higher shear rates are likely to be more relevant to studies of normal cerebral perfusion. Furthermore, the apparent viscosity of blood in very narrow tubes decreases as the diameter of the tube is reduced because of axial migration of the red cells. ${ }^{15}{ }^{16}$ Also, the dynamic haematocrit of blood in the cerebral circulation is less than that measured in a sample from a forearm vein. ${ }^{17}$ Measurements of whole blood viscosity in vitro may therefore overestimate values within the microcirculation. Nevertheless, we can assume that the reduction in whole blood viscosity measured in vitro after plasma exchange was reflected in a corresponding fall in blood viscosity within the cerebral circulation.

Assuming that Poiseuille flow conditions are pertinent to the cerebral microcirculation we would expect a fall in blood viscosity to result in an increase in cerebral blood flow so long as the perfusion pressure and diameter of the vessels remained unchanged. Mean arterial blood pressure was not affected by plasma exchange, and the constancy of cerebral blood flow in these studies, despite a fall in viscosity, must therefore reflect compensatory vasoconstriction. There is ample evidence that the cerebral circulation has considerable powers of homoeostasis, of which autoregulation of cerebral blood flow with respect to changes in perfusion pressure is best known. ${ }^{18} 19$ The present study suggests that a similar autoregulatory mechanism keeps cerebral blood flow constant in the face of changes in blood viscosity. The myogenic theory of autoregulation ${ }^{20}$ could not explain the present findings. On the other hand, the results support the metabolic hypothesis which would predict homoeostasis of blood flow under the stable metabolic conditions of the studies because of the close local coupling of cerebral blood flow to metabolic demands. ${ }^{21}$

A number of authoritative reviews of the physiology of cerebral blood flow have implied that changes in blood viscosity will independently affect the level of cerebral blood flow. ${ }^{22-24}$ The present study throws doubt on this suggestion, which was based on the finding of low cerebral blood flow in patients with polycythaemia who have high whole blood viscosity 222526 and conversely high cerebral blood flow in anaemic patients with low whole blood viscosity. ${ }^{4} 27$ The present results similarly do not support the suggestion that the generalised increase in cerebral blood flow produced by therapeutic haemodilution is due mainly to a reduction in viscosity. ${ }^{28} 29$ The mean whole blood viscosities in this study after plasma exchange were equivalent to the viscosity of blood with normal plasma viscosity and a haemoglobin concentration of approximately $10 \mathrm{~g} / \mathrm{dl}$ and were therefore below those normally achieved by therapeutic haemodilution and similar to those found in mild anaemia. Nevertheless, patients with anaemia and haemodilution also have reduced arterial oxygen content (while patients with primary polycythaemia have a corresponding high arterial oxygen content). Changes in blood oxygen content without changes in viscosity result in changes in cerebral blood flow that keep oxygen transport (cerebral blood flow $\times$ arterial oxygen content) to the tissues constant. ${ }^{.30} 31$ In the present study changes in blood viscosity without changes in arterial oxygen content did not alter the cerebral blood flow. Thus, the changes in cerebral blood flow in polycythaemia, anaemia, and after haemodilution are probably mainly a physiological response to the alterations in oxygen content designed to keep oxygen transport to the brain constant.

Nevertheless, these results in subjects who all had normal cerebral circulation do not necessarily mean that reducing blood viscosity would be of no benefit in acute cerebrovascular disease. Autoregulation of cerebral blood flow to changes in blood pressure may be disrupted after an acute stroke. ${ }^{32}{ }^{33}$ If the autoregulatory mechanism keeping flow constant despite changes in viscosity were similarly affected then therapeutic reduction in viscosity after a stroke could improve local blood flow. Also, changes in viscosity may affect flow in the collateral supply to an area of infarction if there is maximum vasodilatation or vasoparalysis maintained by the ischaemia. ${ }^{34}$ If the viscosity was reduced by haemodilution the increase in flow would have to be greater than the reduction in oxygen content to be of metabolic benefit. The physiological increase in flow expected after haemodilution in normal areas of the brain also threatens undesirable intracerebral steal. ${ }^{35}$ The present study has shown that plasma exchange is an alternative method of lowering blood viscosity that would not affect flow in normal areas of the brain and would be unlikely to cause intracerebral steal. Also, the reduction in fibrinogen, red cell aggregation, and low shear viscosity after plasma exchange might be beneficial in reducing the risk of further thrombosis.

We thank Professor J Newsom Davis for permission to study patients under his care, Dr N Slater for referring one patient from St Thomas's Hospital, Miss Eve Goodger SRN for carrying out the plasma exchange, Miss Sheila Redmond SRN for assisting with the cerebral blood flow measurements, Mr E Zilkha, for maintaining the cerebral blood flow equipment, and Miss Beryl Laatz for secretarial assistance.

\section{References}

${ }^{1}$ Caro CG, Pedley TJ, Schroter RC, Seed WA. The mechanics of the circulation. Oxford: Oxford University Press, 1978.

${ }^{2}$ Begg TB, Hearns JB. Components in blood viscosity. The relative contribution of haematocrit, plasma fibrinogen, and other proteins. Clin Sci 1966;31:87-93.

${ }^{3}$ Gilroy J, Barnhart MI, Meyer JS. Treatment of acute stroke with Dextran 40. ₹AMA 1969;210:293-8.

${ }^{4}$ Gottstein U. Cerebral blood flow, $\mathrm{CMRO}_{2}$ and $\mathrm{CMR}$ of glucose in patients with hypo- and hyperchromic anaemia and polycythaemia. The effect of hemodilution on CBF, CMR and haematocrit. In: Meyer JS, Lechner H, Reivich R, eds. Cerebral vascular disease. Amsterdam: Excerpta Medica, 1978 .

${ }^{5}$ Jones MD, Traystman RJ, Simmons MA, Molteni RA. Effect of changes in arterial $\mathrm{O}_{2}$ content on cerebral blood flow in the lamb. Am $\mathcal{F}$ Physiol $1981 ; 240$ : $\mathrm{H} 209-\mathrm{H} 15$.

${ }^{6}$ Solomon A, Fahey JL. Plasmapheresis therapy in macroglobulinaemia Ann Intern Med 1963;58:789-800.

7 Talpos G, Horrockson M, White JM, Cotton LT. Plasmapheresis in Raynaud's disease. Lancet 1978; ;:416-7.

${ }^{8}$ Kilpatrick D, Fleming J, Clyne C, Thompson GR. Reduction of blood viscosity following plasma exchange. Atherosclerosis 1979;32:301-6.

${ }^{9}$ Thomas DJ, Zilkha E, Redmond S, et al. An intravenous ${ }^{133}$ Xenon clearance technique for measuring cerebral blood flow. $\mathcal{F}$ Neurol $S_{c i}$ $1979 ; 40: 53-63$.

10 Obrist WD, Thompson HK, Wang HS, Wilkinson WE. Regional cerebral blood flow estimated by ${ }^{133}$ Xenon inhalation. Stroke $1975 ; 6: 245-56$.

11 Rice EW, Muesse DER. New accurate, heat precipitation nephelometric method for rapid determination of plasma fibrinogen. Clin Chem 1972 ; 18:73-5.

12 Kelman GR, Nunn JF. Computer produced physiological tables for calculations involving the relationships between blood oxygen tension and content. London: Butterworths, 1968.

13 Chien S, Usami S, Dellenback RJ, Gregersen MI. Shear-dependent interaction of plasma proteins with erythrocytes in blood rheology. $\mathrm{Am}$ F Physiol 1970;219:143-53.

14 Whitmore RL. The flow behaviour of blood in the circulation. Nature 1967;215:123-6.

15 Fahraeus $R$, Lindquist $T$. The viscosity of the blood in narrow capillary tubes. Am 7 Physiol $1931 ; 96$ :562-8.

16 Maude AD, Whitmore RL. Theory of the flow of blood in narrow tubes. f Appl Physiol 1958;12:105-13.

17 Larsen OA, Lassen NA. Cerebral hematocrit in normal man. $\mathcal{F} A p p l$ Physiol $1964 ; 19: 571-4$

18 Harper AM. Autoregulation of cerebral blood flow: influence of the arterial blood pressure on the blood flow through the cerebral cortex. f Neurol Neurosurg Psychiatry 1966;29:398-403.

19 Strandgaard S. Autoregulation of cerebral circulation in hypertension. Acta Neurol Scand 1978;57,suppl 66:1-82.

${ }^{20}$ Purves MJ. The physiology of the cerebral circulation. Cambridge: Cambridge University Press, 1972.

${ }^{21}$ Reivich M. Blood flow metabolism couple in brain. In : Research Publications Association for Research in Nervous and Mental Disease. Plum F, ed. Brain dysfunction in metabolic disorders, vol 53. New York: Raven Press, 1974:125-40.

${ }^{22}$ Kety SS. Circulation and metabolism of the human brain in health and disease. $A m \mathcal{F}$ Med 1950;8:205-17. 
${ }^{23}$ Lassen NA. Control of cerebral circulation in health and disease. Circ Res $1974 ; 34: 749-60$

${ }^{24}$ Gilroy J, Meyer SJ. Medical neurology, 3rd ed. New York: McMillan Publishing Co, 1979:545.

25 Nelson D, Fazekas JF. Cerebral blood flow in polycythaemia vera. Arch Intern Med 1956;98:328-31.

${ }^{26}$ Thomas DJ, du Boulay GH, Marshall J, et al. Cerebral blood flow in polycythaemia. Lancet 1977 ;ii:161-3.

${ }^{27}$ Heyman A, Patterson JL, Duke TW. Cerebral circulation and metabolism in sickle cell and other chronic anaemias, with observations on the effects of oxygen inhalation. $\mathcal{F}$ Clin Invest $1952 ; 31: 824-8$.

28 Gottstein U, Held K. The effect of haemodilution caused by low molecular weight dextran on human cerebral blood flow and metabolism. In: Brock M, Fieschi C, Ingvar DH, et al, eds. Cerebral blood flow. Berlin, Heidelberg, New York: Springer, 1969:104-5.

29 Heiss W-D, Prosenz P, Tschabitscher H, Lasek C, Herles HJ. Effect of low molecular dextran on total cerebral blood flow and on regional flow within ischemic brain lesions. Eur Neurol 1972;8:129-33.
${ }^{30}$ Kety SS, Schmidt CF. The effects of altered arterial tensions of carbon dioxide and oxygen on cerebral blood flow and cerebral oxygen consumption of normal young men. $\mathcal{F}$ Clin Invest $1948 ; 27: 484-92$.

${ }^{31}$ Paulson OB, Parving HH, Olesen J, Skinhøj E. Influence of carbon monoxide and of hemodilution on cerebral blood flow and blood gases in man. F Appl Physiol 1973;35:111-6.

${ }^{32}$ Meyer JS, Shimazu R, Fukuuchi Y, et al. Impaired neurogenic cerebrovascular control and dysautoregulation after stroke. Stroke 1973;4: 169-86.

${ }^{33}$ McHenry LC, West JW, Cooper ES, et al. Cerebral autoregulation in man. Stroke $1974 ; 5: 695-706$

${ }^{34}$ Harrison MJG, Pollock S, Kendall BE, Marshall J. Effect of haematocrit on carotid stenosis and cerebral infarction. Lancet 1981 ;i:114-5.

${ }^{35}$ Høedt-Rasmussen $\mathrm{K}$, Skinhøj E, Paulson $\mathrm{O}$, et al. Regional cerebral blood flow in acute apoplexy. Arch Neurol 1967;17:271-81.

(Accepted 11. March 1982)

\title{
Effect of transdermally administered hyoscine methobromide on nocturnal acid secretion in patients with duodenal ulcer
}

\author{
R P WALT, C J KALMAN, R H HUNT, J J MISIEWICZ
}

\begin{abstract}
Use of anticholinergic drugs in treatment of duodenal ulcers is limited by the side effects of widespread parasympathetic blockade evoked by usual therapeutic doses. A study was conducted into the effectiveness of transdermal delivery of hyoscine methobromide using a new system which releases the drug into the circulation at a controlled rate. In six patients whose duodenal uilcer had healed secretion of acid was measured over two nights, the first on placebo and the second on hyoscine methobromide. All patients responded to the active drug and showed a significant inhibition of acid secretion. Four subjects complained of a dry mouth after overnight treatment with hyoscine methobromide; no other side effects were reported.
\end{abstract}

Transdermal delivery of anticholinergic drugs may be useful in maintenance treatment of duodenal ulcers and further clinical tests are indicated.

\section{Introduction}

Anticholinergic drugs have been used extensively in the treatment of duodenal ulcers, but less so after the introduction of derivatives of liquorice and histamine $\mathrm{H}_{2}$-receptor antagonists ${ }^{1-3}$ and the renewal of interest in complexed bismuth." Though anticholinergics decrease basal, nocturnal, and stimulated acid output in patients with and without duodenal ulcers, ${ }^{156}$ their use is severely limited by side effects of widespread para-

Department of Gastroenterology, Central Middlesex Hospital, London NW10 7NS

R P WALT, MB, MRCP, research fellow and honorary registrar (present address: Academic Department of Medicine, Royal Free Hospital, London NW3 2QG)

J J MISIEWICZ, MB, FRCP, consultant physician

Royal Naval Hospital, Haslar, Hants

C J KALMAN, MB, CHB, surgeon lieutenant

R H HUNT, MB, FRCP, consultant physician and gastroenterologist sympathetic blockade evoked by the usual therapeutic doses. $\vec{N}$ These effects may be produced by blood concentrations of anticholinergics that exceed the concentrations necessary for gastric secretory inhibition, but they are inescapable if drugs are administered in conventional tablet form. We report on an anticholinergic drug (hyoscine methobromide) given using a new transdermal therapeutic system ${ }^{2}$ (Transderm V, CIBA Pharmaceutical Company) that delivers the drug into the circulation at a controlled, predetermined rate. This treatment effectively inhibited nocturnal secretion of acid in patients with duodenal ulcer.

\section{Patients and methods}

Transdermal therapeutic system is a multilayer laminate $2.5 \mathrm{~cm}^{2}$ in area and $200 \mu \mathrm{m}$ thick (fig 1 ). The system comprises a drug reservoir containing hyoscine methobromide in a polymeric gel, surrounded by an impermeable backing membrane and a microporous membrane, which controls the rate of release. It is fastened to the skin by an adhesive layer, which also acts as a reservoir for a priming dose of hyoscine methobromide. The microporous membrane allows hyoscine methobromide to be released at a constant rate of $4 \mu \mathrm{g} / \mathrm{cm}^{2} / \mathrm{h}$ and delivers $0.5 \mathrm{mg}$ of hyoscine methobromide at a steady rate for $72 \mathrm{~h}$. The system was worn by the patients behind the ear, as studies have shown the skin in this region to be most permeable to hyoscine methobromide.

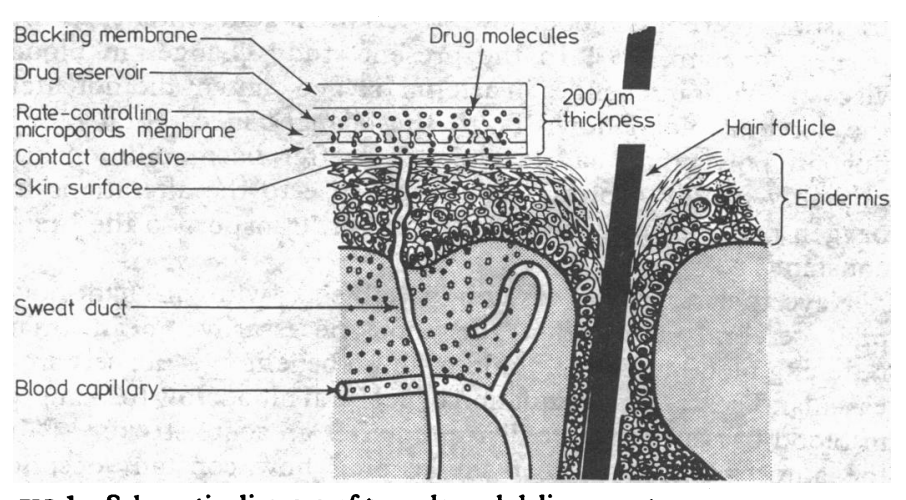

FIG 1-Schematic diagram of transdermal delivery system. 